\title{
Evaluation of a self-management plan for chronic obstructive pulmonary disease
}

\author{
P.B. Watson*, G.I. Town**, N. Holbrook**, C. Dwan*, L.J. Toop ${ }^{+}$, C.J. Drennan*
}

Evaluation of a self-management plan for chronic obstructive pulmonary disease. P.B. Watson, G.I. Town, N. Holbrook, C. Dwan, L.J. Toop, C.J. Drennan. CERS Journals Ltd 1997.

ABSTRACT: We hypothesized that the use of an Action Plan might assist selfmanagement for patients with chronic obstructive pulmonary disease (COPD).

A pilot process and randomized, controlled study were undertaken to evaluate an Action Plan that provided advice on management of usual care and exacerbations, together with a booklet on self-management. Fifty six subjects with COPD recruited through general practitioners (GPs) completed the 6 month study, 27 in the control group and 29 in the intervention group. The control group received usual care from their GP, and the intervention group received a booklet and Action Plan from their practice nurse plus a supply of prednisone and antibiotic from their GP.

The two groups were demographically similar with a mean age of $68 \mathrm{yrs}$. The resources were well received by GPs, practice nurses and intervention group subjects. After 6 months, there were no differences in quality of life scores or pulmonary function. There were significant changes in self-management behaviour in the intervention group compared to controls. In response to deteriorating symptoms, 34 versus $7 \%(p=0.014)$ initiated prednisone treatment and 44 versus $7 \%$ $(p=0.002)$ initiated antibiotics.

Subjects in the intervention group readily adopted self-management skills but did not show any difference in quality of life or lung function parameters. A larger, prospective, controlled, clinical trial of this approach is warranted. Eur Respir J 1997; 10: 1267-1271.
*Canterbury Respiratory Services, Canterbury Health, Christchurch, New Zealand. **The Canterbury Respiratory Research Group, Christchurch, New Zealand. +Dept of Public Health and General Practice, Christchurch School of Medicine, Christchurch, New Zealand.

Correspondence: P.B. Watson

9 Toorak Ave

Christchurch 8004

New Zealand

Keywords: Lung disease (obstructive) New Zealand

patient education

primary care

quality of life

self-management

Received: June 51996

Accepted after revision February 21997

This study was part funded by the Southern Regional Health Authority. Additional funding and resources were provided by The Canterbury Respiratory Research Group.
Chronic obstructive pulmonary disease (COPD) is a major cause of mortality and morbidity worldwide [1, 2]. Although the exact prevalence of COPD is not known, it is amongst the most common causes of death in adults and the mortality rate is projected to rise in Europe over the next decade [3]. Because loss of lung function may be advanced before symptoms develop, it is probable that early COPD is underdiagnosed in the general population [4].

In New Zealand public hospitals, COPD is the third most common discharge diagnosis for males and the eighth most common for females [5]. Its economic impact is substantial. COPD is the eleventh most expensive public hospital discharge diagnosis, with an average inpatient cost of NZ \$4,690. New Zealand's total hospital cost for COPD was estimated to be NZ \$28 million in 1991 [6].

In advanced disease, exacerbations and respiratory failure often necessitate hospital admission and prolonged treatment. However, for the majority of those with COPD, impaired quality of life may be a more important determinant of health care utilization [7]. Many of the problems associated with COPD are managed in the homes of those affected. Key people involved in primary care are the patients themselves, their families, the general practitioner (GP) and practice nurse (PN). There are no published data on the level of COPD morbidity in the New Zealand community, and no systematic description of the management of COPD in primary care.

In the management of many chronic illnesses, increasing attention is being given to patient education and the development of self-management skills. Recent consensus statements on the management of COPD advocate a partnership approach to education, encouraging active involvement by patients, their families and healthcare workers directed at changing behaviour, which could improve quality of life $[1,2]$. The effectiveness of selfmanagement plans, where health professionals provide written guidelines to assist patients with decision-making, has been demonstrated in asthma $[8,9]$. So far, little or no information has been published on the use of self-management plans in patients with COPD. Given the chronic nature of the disease and the similarities between the medical treatment of asthma and COPD, it seemed reasonable to hypothesize that self-management plans may be effective in the long-term management of patients with COPD.

The aims of the study were to evaluate the process of using the COPD Action Plan and booklet in general practice, and to determine the acceptability and efficacy of these approaches in the primary care management of COPD. 


\section{Materials and methods}

The COPD Action Plan (fig. 1) and booklet evaluated in this study were developed by staff from Canterbury Respiratory Services. During 1992, consultation about the resources was initiated with patients, their families,

a)

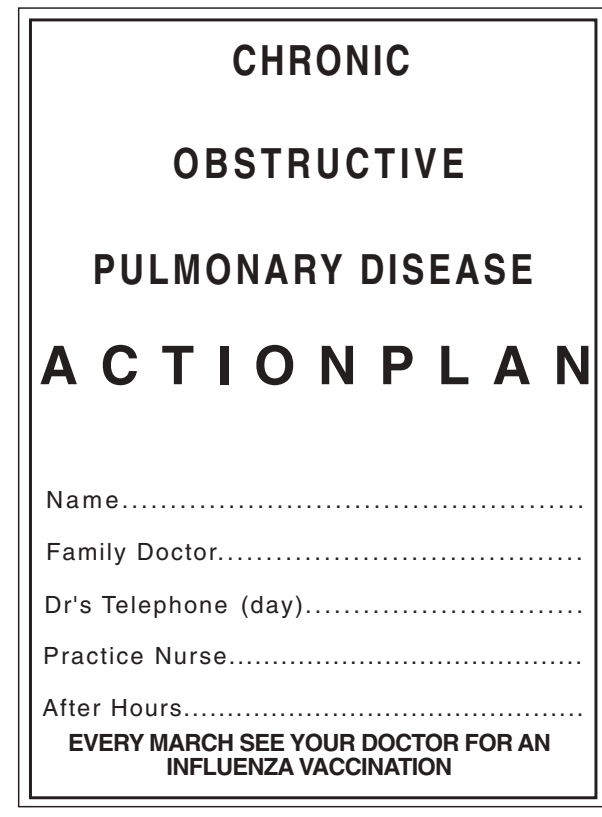

This action plan has been prepared by Respiratory Outreach,

Canterbury Respiratory Services,

Private Bag 4710,

Christchurch.
GPs and PNs. The initial content of the Action Plan was established by the patients and families. The format for the Action Plan was modelled on the asthma action plan produced by the Asthma Foundation of New Zealand [9]. Feedback from workshops with GPs and PNs, and interviews with patients led to modifications to the Action Plan.

b)

\begin{tabular}{|c|}
\hline $\begin{array}{l}\text { MEDICATION OPTIONS FOR } \\
\text { WORSENING SYMPTOMS }\end{array}$ \\
\hline 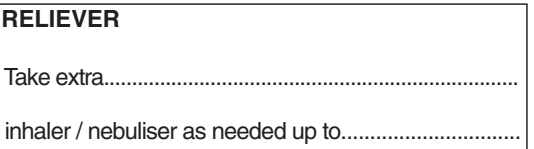 \\
\hline 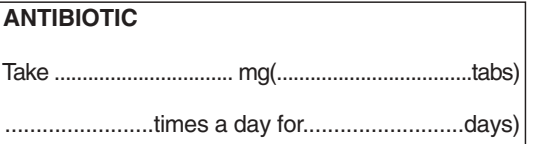 \\
\hline 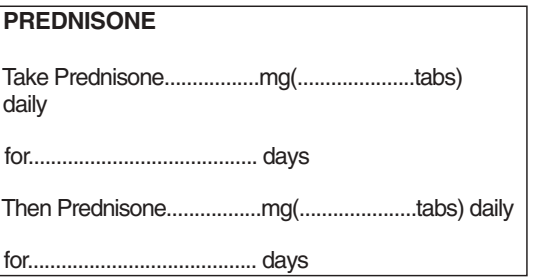 \\
\hline $\begin{array}{c}\text { CONTACT your doctor if you are } \\
\text { not getting better }\end{array}$ \\
\hline 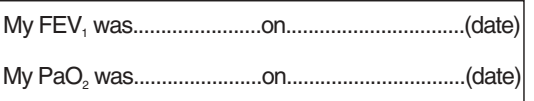 \\
\hline Carry this card when visiting your doctor \\
\hline
\end{tabular}

c)

ACTION PLAN FOR PEOPLE WITH CHRONIC OBSTRUCTIVE PULMONARY DISEASE

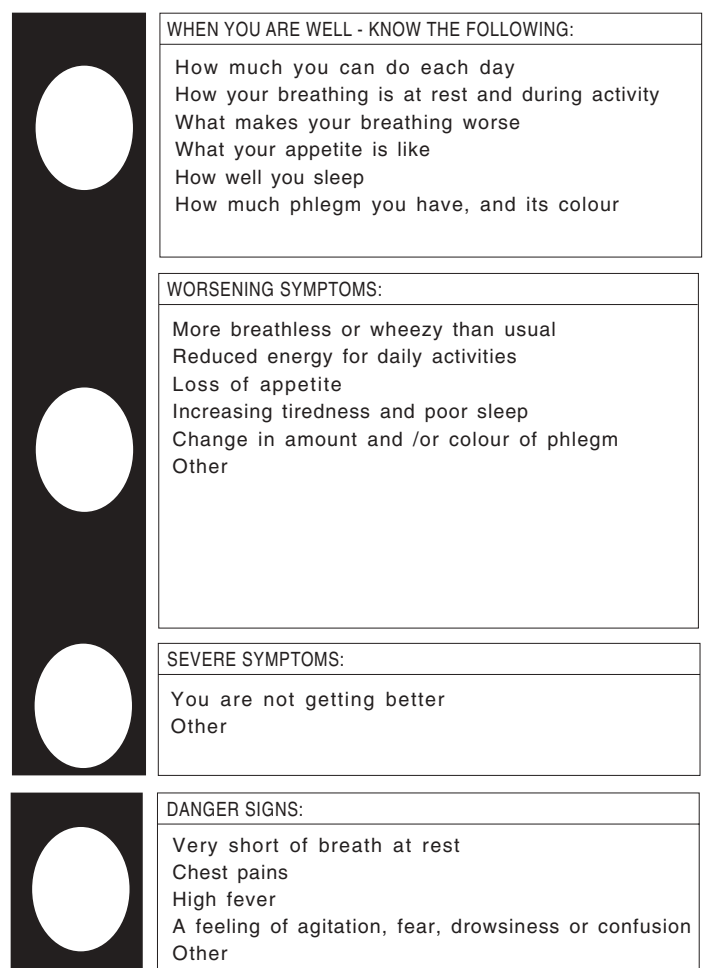

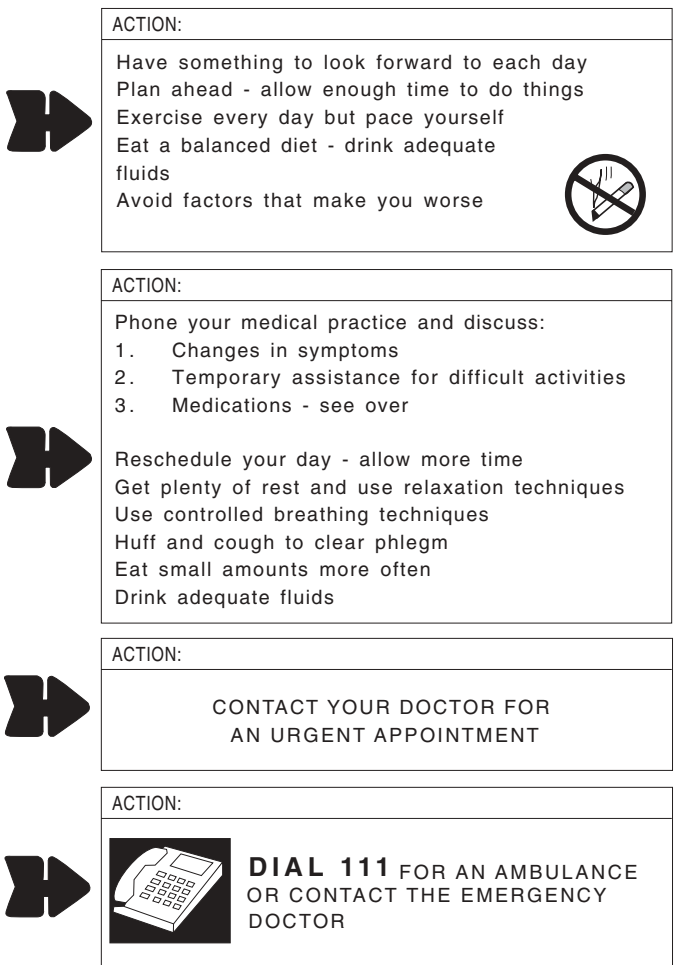

Fig. 1. - a) front ; b) rear; and c) inside of Action Plan card, with spaces for peak expiratory flow values to be entered together with personalized instructions. 
The booklet, entitled "A Guide to Living Positively with Chronic Obstructive Pulmonary Disease", was developed to be used in conjunction with the Action Plan. Existing patient education material was reviewed together with appropriate scientific literature. The topics included in the booklet were: stopping smoking; controlling breathlessness; exercise; daily activities made easier; diet; sleep; clearing mucus from the lungs; planning for the future; medications; oxygen; and contact details for support services. Drafts of the booklet were circulated among patients, their families, respiratory health professionals and PNs for comment.

\section{Study design}

The evaluation project comprised two complementary phases. The first phase was a process of evaluation of the use of the Action Plan and booklet in general practice. This comprised questionnaires sent to GPs and PNs and three telephone interviews with subjects in the intervention group. The second phase was a pretest, post-test outcome evaluation, with random assignment of subjects to either usual care or enhanced care incorporating the use of the Action Plan and booklet. The study was of 6 months duration and was performed during 1994.

\section{Subjects}

Recruitment was achieved through liaison with GPs and PNs. An outline of the study protocol and a copy of the Action Plan and resource booklet were sent to interested GPs and PNs. Appointments were then made to visit them and discuss the study. Patient records were screened by practice staff in relation to the entry and exclusion criteria. Potential subjects were sent a letter and information sheet signed by their GP inviting interested patients to contact the researchers and attend a screening clinic at the practice. Subjects with COPD defined according to American Thoracic Society (ATS) criteria [2] were eligible. Entry criteria were: diagnosis of COPD as the major functionally limiting disease; smoking history of greater than 10 pack-years; forced expiratory volume in one second (FEV1) less than $65 \%$ of predicted; ratio of $\mathrm{FEV} 1$ /forced vital capacity (FVC) less than $70 \%$; and current use of bronchodilator therapy. Exclusion criteria were: primary diagnosis of asthma (onset $<35$ yrs); primary diagnosis of cardiac disease (uncontrolled heart failure); primary or secondary diagnosis of another functionally limiting disease (except cor pulmonale), that could significantly affect either patient mortality within 6 months of entry to the study (e.g. malignant neoplasm) or participation in the study (e.g. confusional states, psychoses); continuous use of oral corticosteroid; long-term antibiotic therapy; and resthome residents. Subjects meeting the entry criteria were randomly allocated either to the intervention or control group. The study was approved by the Southern Regional Health Authority's Canterbury Ethics Committee and all subjects gave written informed consent.

\section{Intervention group}

PNs were educated about the use of the Action Plan and booklet by a senior nurse from the hospital respiratory outreach service. The PN then introduced subjects to the Action Plan and booklet. The GP also saw each subject and gave them a prescription for a course of oral prednisone and a broad spectrum antibiotic appropriate for self-administration during an exacerbation. No attempt was made to supervise the adequacy of the instruction given to subjects.

\section{The "Usual Care" control group}

Subjects in the control group received usual care from their GP. No attempt was made to change the usual care provided by GPs or PNs. Subjects in the control group were specifically denied access to the Action Plan and booklet.

\section{Outcome measures}

Daily diary cards required subjects to rate their respiratory status on a four-point scale, using the categories: usual, mild, moderate or severe. The diary card also recorded: prednisone use; antibiotic use; contact with GP, PN, hospital specialist, pharmacist; and other comments. Subjects were interviewed about their access to and use of a variety of treatments, services and self-management strategies. The St George's Respiratory Questionnaire (SGRQ) [10] was given to subjects at the screening clinic and prior to the exit clinic to self-administer at home. FEV1 and FVC were measured using a spirometer (Vitalograph Alpha; Vitalograph Ltd., Buckingham, UK). Application of the outcome measures was delayed if the subjects had received a course of prednisone or a course of antibiotics in the preceding 21 days.

\section{Statistical analysis and power calculations}

JONES et al. [10] suggest that a difference in total SGRQ score of four points would indicate clinically significant differences between populations and a change of seven points would be "quite large". Assuming significance at the 0.05 level and power of 0.8 , a prospective power calculation indicated a sample size of 166 would be necessary to detect a change of 5.7 points in the total score of the SGRQ. Continuous data are presented as mean and standard deviation and comparisons by Student's t-tests. A p-value less than 0.05 was considered significant. Data from symptom diaries were compared using nonparametric tests. Computational procedures used the Statistical Analysis System (SAS) statistics program.

\section{Results}

\section{Subjects}

Twelve practices (22 GPs) screened 93 subjects for possible inclusion in the study. Twenty four patients did not fit the inclusion criteria and 69 patients were enrolled. Uncertainty regarding study funding and difficulty in recruiting GPs resulted in a decision, during July 1994 , to stop further recruitment. Thirteen patients 
withdrew from the study: four patients were offended by the questionnaires; three patients experienced complications from concurrent medical problems; three felt the study protocol was too demanding; one left the country; and two died. Fifty six patients completed the study, 27 in the control group and 29 in the intervention group. Demographic data are presented in table 1. There were no statistically significant differences in demographic or baseline functional status between the intervention and control groups.

\section{Outcome evaluation}

Assessments were made at baseline and after 6 months. Baseline access to and use of a variety of treatments, services and self-management strategies showed no statistically significant difference between the two groups, except for influenza vaccination (table 1). At the completion of the study, $34 \%$ of subjects in the intervention group had initiated prednisone treatment when they felt they were deteriorating, compared with $7 \%$ in the control group $(\mathrm{p}=0.014)$. Forty four per cent of subjects in the intervention group had initiated antibiotic therapy when they felt they were deteriorating and when their sputum changed colour, compared with $7 \%$ in the control group $(\mathrm{p}=0.002)$.

The results of the SGRQ are presented in table 2. No significant differences were detected when comparing the two groups. However, for the intervention group there was a significant difference in the mean SGRQ total score over time. In addition, the entire study population showed a statistically significant improvement in the SGRQ symptom score over time.

After 6 months, mean (SD) FEV1 was 37 (14)\% pred for the intervention group and 38 (15)\% pred for the control group. There were no significant differences in lung function between the two groups.

Table 1. - Baseline and demographic characteristics

\begin{tabular}{lcc}
\hline Characteristic & $\begin{array}{c}\text { Intervention } \\
\text { group } \\
(\mathrm{n}=29) \\
\%\end{array}$ & $\begin{array}{c}\text { Control } \\
\text { group } \\
(\mathrm{n}=27) \\
\%\end{array}$ \\
\hline Age yrs & $68(10)$ & 67 \\
Male & 62 & 67 \\
Married & 52 & 37 \\
Current smoker & 24 & 33 \\
FEV1 \% pred (sD) & $37(14)$ & 36 \\
Access to a nebulizer & 17 & 26 \\
Own a peak flow meter & 76 & 70 \\
Influenza vaccination in last year & $72 *$ & 44
\end{tabular}

FEV1: forced expiratory volume in one second; $\%$ pred: percentage of predicted value. $*: \mathrm{p}<0.05$, compared to control group.

Table 2. - The St George's Respiratory Questionnaire

\begin{tabular}{lcccc}
\hline Score & \multicolumn{2}{c}{$\begin{array}{c}\text { Intervention group } \\
(\mathrm{n}=29)\end{array}$} & \multicolumn{2}{c}{$\begin{array}{c}\text { Control group } \\
(\mathrm{n}=27)\end{array}$} \\
& Before & After & Before & After \\
\hline Activity score & $55(21)$ & $53(24)$ & $50(22)$ & $51(25)$ \\
Impact score & $28(14)$ & $25(15)$ & $25(17)$ & $26(15)$ \\
Symptom score & $66(20)$ & $58(21)$ & $61(20)$ & $59(21)$ \\
\hline Total score & $43(15)$ & $39(17)$ & $39(16)$ & $39(16)$ \\
\hline
\end{tabular}

Values are presented as mean, and SD in parenthesis.
Table 3. - Symptom diary and medical treatment

\begin{tabular}{lrr}
\hline Variable & $\begin{array}{c}\text { Intervention } \\
\text { group } \\
(\mathrm{n}=29)\end{array}$ & $\begin{array}{c}\text { Control } \\
\text { group } \\
(\mathrm{n}=27)\end{array}$ \\
\hline Days in study n & $186(13)$ & $187(7)$ \\
Days recorded on symptom diary n & $144(62)$ & $160(51)$ \\
Breathing recorded as "usual" \% & $56(37)$ & $51(37)$ \\
\multicolumn{1}{c}{ "mild" \% } & $18(19)$ & $21(24)$ \\
\multicolumn{1}{c}{ "moderate" } & $17(24)$ & $20(26)$ \\
"severe" \% & $8(21)$ & $8(13)$ \\
Days on antibiotics n & $10 *(11)$ & $4(6)$ \\
Days on prednisolone n & $15(22)$ & $9(22)$ \\
Visits to GP or PN n & $3(3)$ & $2(3)$ \\
\hline
\end{tabular}

Values are presented as mean, and SD in parenthesis. GP: general practitioner; $\mathrm{PN}$ : practice nurse. *: $\mathrm{p}<0.05$, compared to control group.

Data from symptom diaries are presented in table 3 There were no significant differences between the groups in the proportion of days rated mild, moderate and severe. The intervention group spent $10 \%$ of days recorded on antibiotics compared with $4 \%$ in the control group $(\mathrm{p}=$ 0.016).

\section{Process evaluation}

Subjects. Eighty five per cent of subjects were given the Action Plan and booklet by their PN. All subjects spent less than 60 min with their PN or GP learning about the Action Plan, with $40 \%$ spending 10-20 min and 35\% spending 20-30 min. None of the participants reported any difficulty understanding the Action Plan when their PN or GP explained it to them. Ninety per cent of participants had either a positive or a very positive reaction to the Action Plan. Eighty five per cent of participants felt the Action Plan helped them to manage their breathing problems better, $10 \%$ were unsure, and $5 \%$ thought that it did not help.

Health professionals. Twenty two questionnaires were posted to participating GPs and 11 to PNs. Twenty responses were received (61\%), nine from GPs and eleven from PNs. Most (94\%) GPs and PNs had no difficulty explaining the Action Plan to their patients. For the $6 \%$ who had difficulty explaining the plan, the main problem was the additional time required for explanation. Of the GPs and PNs who indicated they had used the Action Plan with their patients, all were happy to continue using the Action Plan.

\section{Discussion}

The Action Plan and booklet were received positively by patients, their GPs and PNs. They all found the Action Plan and booklet helped with the introduction of self-management skills. Subjects in the intervention group demonstrated acquisition of self-management skills. No significant differences were detected between the two groups for the SGRQ. However, the four point improvement in the SGRQ total score for the intervention group represents a statistically significant improvement. Since the actual sample size was smaller than originally calculated, a retrospective power calculation was performed. 
Assuming significance at 0.05 and power at $80 \%$, the power calculation indicated a sample size of 62 subjects in each group would have been required to detect a change between populations of four points in the SGRQ total score.

The four point change in the SGRQ total in the intervention group may represent a clinically significant change. Two different approaches have been used to describe the clinical significance of changes in SGRQ total score. One model utilized multivariate regression, in which the SGRQ total score from 141 patients with airflow limita-tion was related to clinically relevant changes in a range of disease-related variables, including 6-min walking distance, frequency of wheeze, and Medical Research Council (UK) dyspnoea grade [10]. The second model assessed the size of a clinically significant change from the patient's perspective [11]. Patients completed the SGRQ at the beginning and end of a large, randomized, controlled trial of nedocromil sodium. At the end of the study they also assessed the efficacy of the intervention using a five-point scale. Both studies suggested that a clinically significant change in SGRQ total score is around 4 points. The statistically significant difference in the SGRQ symptom score for the whole study population between the beginning and end of the study is most likely associated with a seasonal variation in symptoms. The study began in early winter and ended in midsummer.

A potential confounding factor in interpreting the results is that at baseline, despite randomization, the intervention group was significantly $(\mathrm{p}=0.034)$ more likely to have had an influenza vaccination (intervention group $72 \%$ and control group $44 \%$ ). It is also likely that the self-selected sample of GPs and PNs who recruited patients for the study are a biased sample, with an interest either in COPD or research. At baseline, it was common practice for all GPs in the study to give their more severe COPD patients prednisone and or antibiotic to self-administer during an exacerbation. As this was the major pharmacological intervention being promoted by the Action Plan, the difference between normal practice and enhanced practice with the Action Plan and booklet may have been less than amongst a larger random sample of GPs. It is also possible that GPs and PNs in the study changed their usual care for patients in the control group even though they did not specifically use the Action Plan and booklet. One way to overcome these difficulties would be to design a cluster controlled study where GPs, rather than their patients, are randomized to intervention or control groups.

Only a few studies have evaluated the important role of the general practitioner and practice nurse in the community management of COPD $[12,13]$. The results of the present study support the positive role for PNs and GPs in helping people with COPD to improve self-management skills.

In conclusion, our study has demonstrated the positive effects on self-management skills of a COPD Action Plan and booklet implemented in general practice for people with chronic obstructive pulmonary disease. However, like similarly constructed studies, it has failed to show that changes in self-management result in improved quality of life or lung function. A larger prospective controlled clinical trial of this approach that includes outcome measures for family members and a cost-benefit analysis is warranted.

Acknowledgements: The authors are indebted to the people with COPD who participated in the study and to the Practice Nurses and General Practitioners who gave generously of their time and energy in assisting with the study.

\section{References}

1. Siafakas NM, Vermeire P, Pride NB, et al. Optimal assessment and management of chronic obstructive pulmonary disease (COPD): A consensus statement of the European Respiratory Society. Eur Respir J 1995; 8: 1398-1420.

2. American Thoracic Society. Standards for the diagnosis and care of patients with chronic obstructive pulmonary Disease. Official statement of the American Thoracic Society. Am J Respir Crit Care Med 1995; 152, 5 (Part 2): S78-S121.

3. Peto R, Lopez AD, Boreham J, Thun M, Heath C Jr. Mortality from tobacco in developed countries: indirect estimation from national vital statistics. Lancet 1992; 339: $1268-1278$.

4. Manfreda J, Mas Y, Litven W. Morbidity and mortality from chronic obstructive pulmonary disease. Am Rev Respir Dis 1989; 140: S19-S26.

5. Ministry of Health, New Zealand Health Information Service. Hospital and selected morbidity data. 1992; xii.

6. The National Advisory Committee on Core Health and Disability Support Services, Wellington New Zealand. Core health and disability support services for 1993-1994. First Report of The National Advisory Committee on Core Health and Disability Support Services. 1992; 42.

7. Traver GA. Measures of symptoms and life quality to predict emergency use of institutional health care resources in chronic obstructive airways disease. Heart Lung 1988; 17: 689-697.

8. Beasley R Cushley M, Holgate ST. A self-management plan in the treatment of adult asthma. Thorax 1989, 44: 200-204.

9. Town GI, Hodges ID, Wilkie AT, Toop LJ, Graham P, Drennan CJ. A community wide promotion of asthma self-management in New Zealand. Pat Ed Couns 1995; 26: 219-224.

10. Jones PW, Quirk FH, Baveystock CM. The St George's Respiratory Questionnaire. Respir Med 1991; 85 (Suppl. B): 25-31.

11. Jones PW, Lasserson D. Relationship between change in St George's Respiratory Questionnaire score and patients perception of treatment efficacy after 1 year of therapy with nedocromil sodium. Am Rev Respir Crit Care Med 1994; 149: A211.

12. Strijbos JH, Koeter GH, Meinesz AF. Home care rehabilitation and perception of dyspnoea in chronic obstructive pulmonary disease (COPD) patients. Chest 1990; 97: 109s-110s.

13. Wijkstra PJ, TenVergert EM, van Altana R, et al. Longterm benefits of rehabilitation at home on quality of life and exercise tolerance in patients with chronic obstructive pulmonary disease. Thorax 1995; 50: 824-828. 